\title{
The first incidence of an alien soft coral of the family Xeniidae in the Caribbean, an invasion in eastern Venezuelan coral communities
}
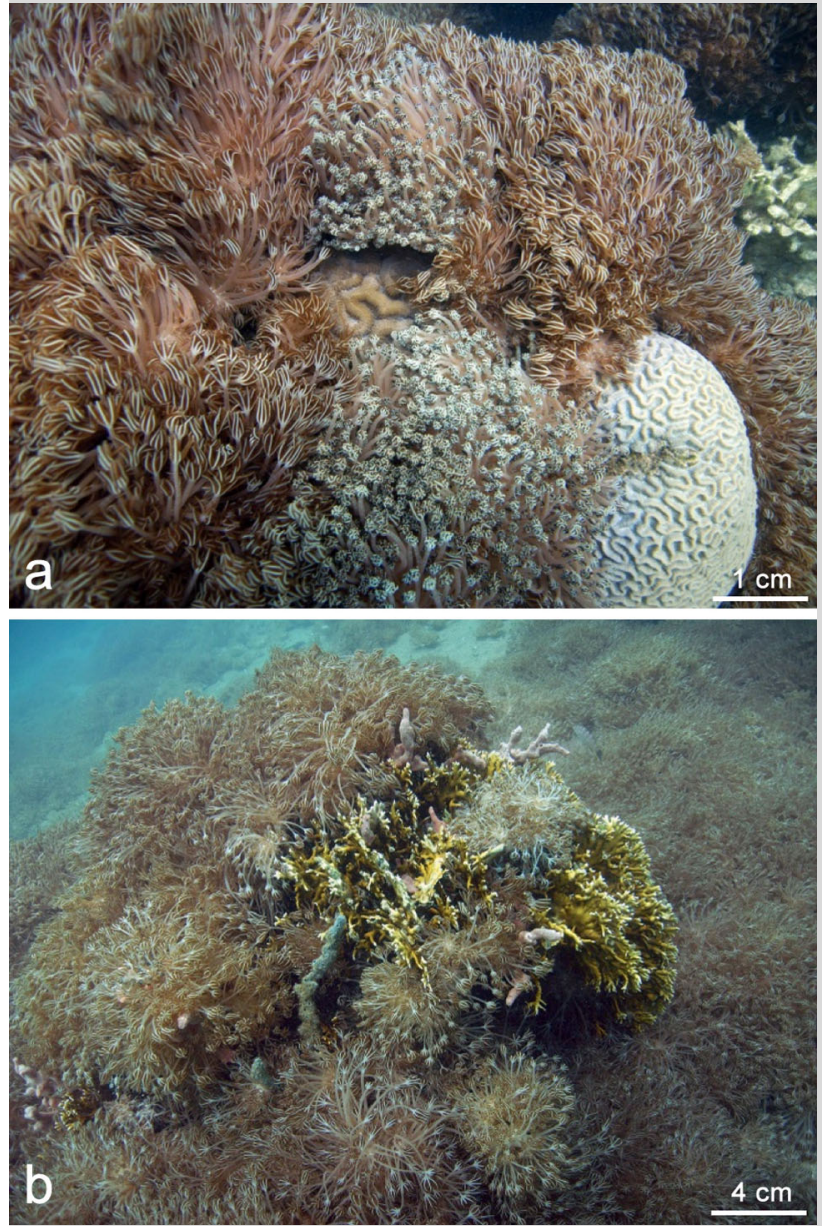

Fig. 1 Venezuelan reefs overgrown by invasive xeniid soft coral: a C. natans (left) D. strigosa (right). b M. alcicornis
Octocorals in family Xeniidae (Ehrenberg, 1828) constitute an abundant component of many Indo-Pacific coral reefs. Several xeniids are ephemeral pioneers, with rapid growth rates, high fecundity, and extensive vegetative reproduction (Benayahu and Loya 1985). There is increased evidence that opportunistic Xeniidae are taking over degraded reef substrata (Tilot et al. 2008) and have thus become highly relevant to ecological processes on coral reefs, affecting their colonization, restoration, and function.

An invasive xeniid soft coral with close genetic affinities to Xenia membranacea Schenk 1896 from Indonesia (C.S. McFadden pers comm) was first found in 2007 on the coastal coral community of Valle Seco (northeast Venezuela, $10^{\circ} 14.6 \mathrm{~N} ; 64^{\circ} 31.70 \mathrm{~W}$ ). At that time, a single colony was found growing on a dead stony coral and subsequently found on coral rubble, sand, and debris. Since then, it has increased in abundance, spreading several $\mathrm{km}$ away to Conoma Bay and Mono Island, occupying $\sim 20 \%$ of the substratum. Abundance fluctuates, with a decrease during the rainy season. This soft coral inhabits both soft and hard substrata, including introduced debris, in well-illuminated habitats $(0.5-4 \mathrm{~m})$. It overgrows scleractinian corals, such as Colpophyllia natans (Fig. 1a), Diploria strigosa (Fig. 1a), Orbicella annularis, Montastraea cavernosa, and the hydrocoral Millepora alcicornis (Fig. 1b), the latter being a principal component of the coral communities. Biodiversity at the sites has deteriorated, mainly due to the loss of living stony coral coverage.

The current findings are the first report of an invasive soft coral of the Xeniidae and its expansion beyond the Indo-Pacific region. It appears to have been illegally introduced into Venezuela by commercial aquarists and intentionally seeded in the rocky substrate for propagation and farming purposes. There has been no attempt to remove the species. The ecological consequences of the invasion, and both spatial and temporal changes in its spread, should undoubtedly be carefully monitored.

Acknowledgments We thank V. Wexler for digital editing and N. Paz for skillful editorial assistance.

\section{References}

Benayahu Y, Loya Y (1985) Settlement and recruitment of a soft coral: Why is Xenia macrospiculata a successful colonizer? Bull Mar Sci 36:177-188 Tilot V, Leujak W, Ormond FG, Ashworth JA, Mabrouk A (2008) Sinai coral reefs: Influence of natural and anthropogenic factors. Aquat Conserv: Mar Freshw Ecosyst 18:1109-1226

J. P. Ruiz Allais

Fundación Costa de Venezuela, Dirección Científica, Caracas, Venezuela

M. E. Amaro

Laboratorio de Bentos, Instituto Oceanográfico de Venezuela, Universidad de Oriente, Cumana, Venezuela

C. S. McFadden

Department of Biology, Harvey Mudd College, Claremont, CA 91711, USA

A. Halász · Y. Benayahu ( $₫)$

Department of Zoology, Faculty of Life Sciences, Tel Aviv University, Ramat Aviv, 69978 Tel Aviv, Israel

e-mail:Yehudab@tauex.tau.ac.il 